\title{
O custeio do sindicato livre: uma análise da compatibilidade das contribuições sindical e assistencial com o princípio da liberdade sindical
}

\author{
The funding of the free trade union: an analysis of \\ the compatibility between the compulsory trade union \\ due and assistential contribution with the freedom of \\ association principle
}

\author{
Ana Virgínia Moreira Gomes* \\ Antônio Alfeu da Silva*
}

\section{Resumo}

O artigo analisa criticamente as principais fontes de custeio dos sindicatos no Brasil, em especial a contribuição sindical compulsória e a contribuição assistencial sindical, considerando seus aspectos históricos, doutrinários e jurisprudenciais, e discutindo a compatibilidade dessas regras com o princípio da liberdade sindical. O estudo examina dois questionamentos acerca do sistema de custeio do sindicato no Brasil - um no Tribunal de Contas da União (TCU) e outro perante a Organização Internacional do Trabalho. O primeiro versa acerca da possibilidade de fiscalização, pelo TCU, da aplicação dos recursos provenientes da contribuição sindical obrigatória, tendo em vista a sua natureza tributária e o seu interesse público. O segundo trata do caso $n^{\circ} 2739$ (Brasil) do Comitê de Liberdade Sindical da OIT, que analisa queixa apresentada por organizações sindicais brasileiras contra o governo brasileiro em razão de medidas tomadas pelo Ministério Público do Trabalho (MPT), em São Paulo, no sentido de anular cláusulas de contribuição assistencial. Conclui-

Doutora pela Universidade de São Paulo. Professora do Programa de Pós-Graduação em Direito Constitucional e do Curso de Direito da Universidade de Fortaleza. Fortaleza - CE - Brasil. Email: avmgomes@gmail.com

* Mestrando em Direito Constitucional pela Universidade de Fortaleza - Unifor. Gerente de Recursos Humanos da Fundação Edson Queiroz. Advogado e negociador sindical/trabalhista. Fortaleza - Ceará - Brasil. Email: aalfeu@hotmail.com 
se que mesmo uma contribuição compulsória para um grupo de trabalhadores pode ser considerada democrática, conforme os princípios da OIT, desde que o sindicato que a instituiu seja um sindicato com representação democrática, e que a contribuição tenha sido resultado de uma decisão da assembleia. Diante do contexto nacional brasileiro, no entanto, deve-se ressaltar que a contribuição assistencial, se somada à já existente contribuição sindical compulsória, adquire contorno de um ato abusivo praticado pelo sindicato contra os próprios trabalhadores.

Palavras-chave: Custeio do sindicato. Liberdade sindical. Contribuição sindical compulsória. Contribuição assistencial sindical. Organização Internacional do Trabalho.

\section{Abstract}

The article critically examines the main sources of trade unions' funding in Brazil, especially the compulsory trade union due and the assistential trade union due, considering its historical, doctrinal and jurisprudential aspects, and discussing the compatibility of those rules with the principle of freedom of association. The study examines two cases that question the trade union's financial funding system in Brazil - one in the Federal Audit Court - TCU and another at the International Labour Organization - ILO. The first deals with the possibility of the $T C U$ assessing the accountable use of the compulsory union due resources by the trade unions, given its fiscal nature and its public interest. The second deals with the case No. 2739 (Brazil) of the ILO Freedom of Association Committee, which examines a complaint presented by Brazilian trade union organizations against the Brazilian government due to measures taken by the Public Labour Prosecutors - MPT, in São Paulo, to void negotiated assistential contribution clauses. The paper concludes that even a trade union due compulsory to a group of workers can be considered democratic, according to the ILO principles, if the trade union that negotiating the contribution has a democratic representation, and that the contribution resulted from a decision of the assembly. Considering the Brazilian national context, however, the assistential trade union due becomes a measure of an abusive nature taken by the union against workers, if we consider that a compulsory trade union due is already in place.

Keywords: Trade union funding. Freedom of association. Compulsory trade union due. Assistential trade union due. International Labour Organization. 


\section{Introdução}

No sistema sindical corporativista brasileiro, a regra da contribuição sindical compulsória foi introduzida em 1939, com o claro intuito de reforçar o controle do sindicato pelo Estado, mais que para garantir o seu sustento financeiro. Assim como as demais regras corporativistas, da unicidade sindical e da imposição da organização por categorias, a regra da contribuição compulsória sobreviveu períodos democráticos e autoritários para, enfim, ser reconhecida pela atual Constituição Federal. Sua longevidade, no entanto, não impede as discussões política e doutrinária acerca da sua compatibilidade com o princípio da liberdade sindical e sobre mecanismos de controle do uso dos respectivos recursos.

Este estudo visa colaborar com essa discussão, ao analisar criticamente o sistema de custeio dos sindicatos no Brasil, sobretudo no que concerne à imposição de contribuições sindicais a trabalhadores não associados, tendo como paradigma o princípio da liberdade sindical e considerando questões referentes à representatividade sindical e ao uso responsável dos recursos provenientes das contribuições.

Para esse fim, examinou-se, inicialmente, o conceito de liberdade sindical a partir dos tratados internacionais sobre o tema, em especial das Convenções $n^{\circ} 87$ e $n^{\circ} 98$ da Organização Internacional do Trabalho - OIT. Considerou-se, ainda, o status jurídico das convenções no ordenamento interno, particularmente diante do $\S 3^{\circ}$ do art. $5^{\circ}$ da Constituição Federal.

A seguir, analisaram-se criticamente as principais fontes de custeio dos sindicatos no Brasil, em especial a contribuição sindical compulsória e a contribuição assistencial sindical, considerando-se os seus aspectos históricos, doutrinários e jurisprudenciais, discutindo-se a compatibilidade dessas regras com o princípio da liberdade sindical.

Nos itens 3 e 4, foram estudados dois questionamentos em face do sistema de custeio do sindicato no Brasil - um no Tribunal de Contas da União (TCU) e outro perante a Organização Internacional do Trabalho 
(OIT). O primeiro incursiona sobre a possibilidade de fiscalização, pelo TCU, da aplicação dos recursos provenientes da contribuição sindical obrigatória, tendo em vista a sua natureza tributária e seu interesse público. Nesse item, analisou-se o Acórdão no Mandado de Segurança - MS n²8.465, do Distrito Federal - DF, do ano de 2014. No item seguinte, analisou-se a contribuição assistencial sindical, a partir da doutrina e da jurisprudência nacionais, bem como discutiu-se o caso $n^{\circ} 2739$ (Brasil) do Comitê de Liberdade Sindical da OIT, envolvendo o Ministério Público do Trabalho (MPT), em São Paulo, e o movimento sindical trabalhista.

\section{A incompatibilidade do sistema sindical brasileiro com - princípio da liberdade sindical e com os tratados internacionais de proteção à liberdade sindical}

A liberdade de associação, mais ampla e genérica, e a liberdade sindical, mais restrita e específica (BERNARDES, 1998), constituemse direitos fundamentais, nacional e internacionalmente reconhecidos, consoante previsão na constituição de $1988^{1}$ e em vários tratados internacionais de direitos humanos ${ }^{2}$, concretizando-se nas relações de trabalho. Destaca-se, dentre os tratados que garantem a liberdade sindical, a Convenção $\mathrm{n}^{\circ} 87$ da OIT sobre Liberdade Sindical, por tratar especificamente do tema, e, ainda, por contar com um órgão internacional, o Comitê de Liberdade Sindical da OIT, que por 64 anos vem interpretando a convenção a partir de casos apresentados à OIT e construindo uma ampla jurisprudência acerca do conteúdo normativo do princípio da liberdade sindical. Complementarmente à Convenção

\footnotetext{
Art. $5^{\circ}:$ XVII - é plena a liberdade de associação para fins lícitos, vedada a de caráter paramilitar; $X X$ - ninguém poderá ser compelido a associar-se ou a permanecer associado; Art. $8^{\circ}$ : É livre a associação profissional ou sindical, observado o seguinte: [...]; V - ninguém será obrigado a filiarse ou a manter-se filiado a sindicato.

2 E.g.: Declaração Universal dos Direitos do Homem, em seu Artigo XXIII, n 4; No Pacto Internacional dos Direitos Civis e Políticos (PIDCP) da ONU, e no Pacto Internacional dos Direitos Econômicos, Sociais e Culturais (PIDESC) da ONU.
} 
$n^{\circ} 87$, a Convenção $n^{\circ} 98$, também da OIT, visa garantir o direito à plena negociação coletiva e proteger os trabalhadores contra condutas

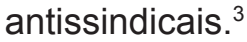

O Brasil ainda não ratificou a Convenção $n^{\circ} 87,{ }^{4}$ no que pese já haver ratificado uma série de outros tratados internacionais que reconhecem a liberdade sindical, como, por exemplo, o PIDESC, promulgado pelo Decreto Presidencial $n^{\circ} 591$, de 6.7.1992. O art. $8^{\circ}$ do referido Pacto praticamente repete as normas de liberdade sindical previstas na Convenção $\mathrm{n}^{\circ} 87$ da OIT. Ademais, o Brasil também ratificou o Protocolo Adicional à Convenção Americana sobre Direitos Humanos em Matéria de Direitos Econômicos, Sociais e Culturais - "Protocolo de São Salvador", internalizando-o no Direito interno, por intermédio do Decreto $n^{\circ} 3.321$, de 30.12.1999. Este Protocolo, também no art. $8^{\circ}$, praticamente repete 0 art. $8^{\circ}$ do Pacto Internacional dos Direitos Econômicos, Sociais e Culturais.

Ao trazer outros importantes exemplos de tratados internacionais que garantem a liberdade sindical, ratificados pelo Brasil, Gacek (2014, p. 130) conclui:

[...] há uma verdade altamente inconveniente em toda essa discussão. Apesar de o Brasil não ter ratificado a Convenção n. 87, ratificou as Convenções 141 (em 1994), 151 (em 2010) e 98 (em 1952), e essas normas da OIT envolvem diretamente os mesmos temas espinhosos.

3 A partir da análise do texto normativo da Convenção $n^{\circ} 87$, do Artigo 80 do PIDESC e do Artigo 22 do PIDCP, pode-se traçar um tríplice aspecto da liberdade sindical, a saber: I - A liberdade sindical coletiva, correspondendo ao direito dos trabalhadores e empregadores... de livremente constituírem os seus sindicatos; II - A liberdade sindical individual, que é o direito que assiste a trabalhadores e empregadores de filiarem-se ao sindicato de sua preferência, bem como dele desfiliar-se quando entender oportuno e conveniente; e III - A autonomia sindical, esta refere-se a liberdade da entidade sindical de se organizar e funcionar livremente, assim como a faculdade de constituir federações e confederações, filiar-se às já existentes, objetivando os fins da instituição (SÜSSEKIND, 2004, p. 364).

4 A mensagem presidencial encaminhando a ratificação da Convenção 87 foi enviada ao Congresso Nacional em 31 de maio de 1949. É o mais antigo projeto na casa. 
Ademais, desde o Tratado de Versalhes, de 1919, cujo art. 427, $\mathrm{n}^{\circ}$ 2, contempla o mencionado direito fundamental, o Brasil ratificou vários outros tratados com conteúdos similares ou idênticos.

A inconveniência a que se refere Gacek trata da incompatibilidade desses tratados com a regra da unicidade sindical prevista no art. $8^{\circ}$, inciso II, da imposição de organização por categorias previstas no inciso III do mesmo artigo, e do reconhecimento da contribuição sindical em seus artigos $8^{\circ}$, IV e 149 (contribuição de natureza tributária de "interesse das categorias profissionais ou econômicas") da Constituição Federal. Tais regras violam o princípio da liberdade sindical ao restringir as dimensões individuais e coletivas dessa liberdade. ${ }^{5}$

No entanto, sendo essas regras textos originários da Constituição, possuem hierarquia superior aos tratados. Mesmo considerando-se a atual posição do Supremo Tribunal Federal de considerar tratados de direitos humanos ratificados anteriormente à Emenda Constitucional $n^{\circ}$ 45 , de 2004 , que inclui o $\S 3^{\circ}$ no art. $5^{\circ}$ da Constituição, com hierarquia supralegal, ${ }^{6}$ esses tratados ainda não teriam o poder de alterar texto constitucional.

Volta-se, assim, para a ratificação da Convenção n 87 como uma possibilidade de reforma do sistema sindical corporativista brasileiro. Almeida (2006, p. 366) entende que o $\S 3^{\circ}$ do art. $5^{\circ}$ da Constituição poderia facilitar a alteração do art. $8^{\circ}$, considerando que a Convenção $\mathrm{n}^{\circ} 87$ da OIT é um "[...] tratado internacional sobre direito humano fundamental e consagrada como liberdade pública, constitui por si só um

5 Para Brito Filho (2009), a liberdade sindical é violada pela rígida estrutura organizativa que, segundo o autor, permanece presa na moldura corporativista da década de 30, pelos institutos da unicidade sindical, da organização por categoria e do sistema confederativo. Embora se possa decidir não participar de um sindicato, não se pode escolher outro de sua preferência, e na prática dificilmente o trabalhador consegue constituir um novo sindicato com a representação legal, os sindicatos não podem organizar-se horizontalmente, entre outras restrições.

6 BRASIL. STF. RE 466.343-1, data da publicação: 05.06.2009. São Paulo - hierarquia abaixo da Constituição, mas acima da legislação interna. 
documento pronto e acabado sobre a liberdade sindical, o que somente favoreceria a sua aprovação". ${ }^{7}$ A Convenção n 87 , se internalizada pela regra do $\S 3^{\circ}$ do art. $5^{\circ}$, entraria no sistema jurídico brasileiro com o status de Emenda Constitucional, alterando assim 0 art. $8^{\circ}$.

Ressalta-se não caber o argumento de que os incisos II e III são textos emanados do poder constituinte originário, não sendo, portanto, passíveis de alteração por norma com hierarquia de emenda constitucional, pois tanto a unicidade, quanto a imposição da organização por categorias não constituem direitos fundamentais. Ao contrário, são limitações a uma liberdade fundamental. Finda a regra da unicidade, a imposição de uma contribuição sindical compulsória desvinculada de qualquer espécie de representatividade democrática não teria mais sentido.

Apesar dessa possibilidade, deve-se reconhecer que a razão da não ratificação da Convenção $n^{\circ} 87$ até hoje não foi a impossibilidade jurídica, mas a falta de vontade política, não só de governos e partidos políticos como também dos próprios sindicatos - de trabalhadores e patronais -, em alterar o atual sistema. A estrutura sindical corporativista, ao mesmo tempo que limita a liberdade sindical dos trabalhadores, garante um grande privilégio ao sindicato: a representação legal mandatória, sem nenhuma correlação com a representatividade de fato, uma vez que o sindicato único que representa a categoria obtém essa representação simplesmente por ter sido o primeiro a requerê-la ao Ministério do Trabalho, sem nenhuma prova efetiva de ter sido escolhido pela maioria da categoria.

Esse privilégio, do qual decorrem vários outros, distorce 0 sistema de representação sindical no Brasil e ao mesmo tempo constitui um lobby poderoso, formado por empregadores, sindicatos, federações, confederações e mesmo centrais sindicais, contrário à ratificação da Convenção $n^{\circ}$ 87. A questão que se coloca neste artigo é se e em

Sobre a ratificação de tratados de direitos humanos no sistema constitucional brasileiro, ver Gomes e Przybyzeski (2014). 
que medida o sistema de custeio também é afetado pelo déficit de representatividade do sistema sindical brasileiro, gerado pelas regras da unicidade e da organização sindical por categoria.

\section{Contribuição sindical compulsória - uma violação ao princípio da liberdade sindical?}

As contribuições sindicais são as principais fontes de custeio dos sindicatos. ${ }^{8}$ A contribuição sindical compulsória é a que tem maior peso na constituição dos recursos das referidas entidades, sobretudo daquelas sem representatividade, as quais dependem quase totalmente desses valores, ficando com a maior parte do que é arrecadado. ${ }^{9}$ Recolhida uma vez por ano, a contribuição sindical é compulsória para trabalhadores empregados, sindicalizados ou não, profissionais liberais, inclusive para o empregador. ${ }^{10} \mathrm{~A}$ contribuição sindical obrigatória tem natureza jurídica de tributo parafiscal, sendo esta uma das razões ensejadoras de muitas críticas em virtude da violação ao princípio da liberdade associativa. ${ }^{11}$

A contribuição sindical é uma das regras mais antigas do Direito do Trabalho brasileiro, integrando o sistema corporativista bem no seu início. $\mathrm{O}$ art. $8^{\circ}$, letras a e $b$, do Decreto $\mathrm{n}^{\circ} 19.770$, de 1931 , autorizava

8 São basicamente quatro as fontes de custeio: a contribuição social, base legal no art. $548, b$, CLT; a contribuição assistencial sindical, previsão genérica no art. 513, e, CLT; a contribuição confederativa, prevista no art. $8^{\circ}$, IV, CF; e a contribuição sindical obrigatória, instituída por lei arts. 578 a 610 da CLT - a qual também está respaldada no art. $8^{\circ}$, IV, e no art. 149, CF de 1988.

9 O Art. 589 da CLT dispõe sobre o rateio da receita da contribuição sindical: $60 \%$ para o sindicato; $15 \%$ para a federação; $5 \%$ para a confederação; $10 \%$ para a central sindical; e $10 \%$ para o Estado.

10 Exceção feita a alguns trabalhadores, e.g.: profissional liberal que paga a contribuição sindical a entidade representativa da sua profissão, desde que a exerça na empresa na qual seja empregado e como tal seja nesta registrado, nos termos do art. 585 da CLT. O advogado empregado é um caso especial. Este, estando quite com a $O A B$, não precisa sofrer o desconto em folha, consoante previsão no art. 47 da Lei n 8.906 de 1994.

11 Quanto à sua natureza jurídica tributária, há um consenso doutrinário e jurisprudencial, inclusive no Supremo Tribunal Federal (STF), consoante acórdão no RE n 180.745-8. Data da publicação: 08.05.1998. 
os sindicatos a requererem ao Ministério do Trabalho "medidas de proteção, auxílios, subvenções para os seus institutos de assistência e de educação [...]". O Decreto n²4.694, de 1934, praticamente reproduziu a redação do Decreto n 19.770, de 1931. A Constituição de 1934 passou in albis nesse assunto, mas a Constituição de 1937 não - ao atribuir, no art. 138, poderes ao sindicato para celebrar contratos coletivos para os seus associados, impor-lhes contribuições e exercer funções delegadas do poder público. Observe-se que enquanto o Decreto $n^{\circ} .19 .770$ de 1931 , art. $5^{\circ}$, apenas assegurava ser o sindicato um órgão consultivo do Estado, a Constituição de 1937 dá letras finais na instituição do modelo corporativo, sobretudo quando atribui ao sindicato funções delegadas do poder público.

Um pouco mais adiante, o Decreto-Lei $n^{\circ} 1.402$, de 1939, art. $3^{\circ}$, estabeleceu que os sindicatos poderiam "[...] impor contribuições a todos aqueles que participam das profissões ou categorias representadas". Essa redação posteriormente passou a integrar a CLT, alínea e do art. 513. Ademais, o art. 35 do mesmo Decreto-Lei determinou que "[...] os empregadores ficam obrigados a descontar na folha de pagamento dos seus empregados as contribuições por estes devidas ao sindicato". Todavia, somente a partir de 1940, por meio do Decreto-Lei $n^{\circ} 2.377$, art. $2^{\circ}$, foi criado o imposto sindical, de natureza tributária, alcançando a todos os empregados e empregadores, sindicalizados ou não ${ }^{12}$. A diferença básica entre as contribuições previstas no Decreto-Lei $n^{\circ}$ 1.402, de 1939, e o imposto sindical é que este é propriamente um tributo, instituído por lei, e aquelas são contribuições privadas, autorizadas por lei, mas instituídas conforme decidido em assembleia da entidade sindical instituidora.

A Constituição de 1946 não tratou do tema, mas manteve a concessão ao sindicato de funções delegadas do poder público em seu art. 159, i.e., permaneceu o mesmo regime no que se refere às

12 O imposto sindical rural foi criado pela Lei $n^{\circ} 4.214$ de 1963, art. 135, remetendo ao disciplinamento já existente na CLT. 
relações sindicais. O Decreto-Lei $n^{\circ} 27$, de 1966, acrescentou o art. 217 à Lei n 5.172 do mesmo ano (Código Tributário Nacional - CTN), denominando o imposto sindical de contribuição sindical. Mudou-se somente o nomem juris, mantendo-se a mesma natureza tributária, o que Delgado (2008) chamou de "epíteto mais eufemístico". Essa nova definição foi internalizada na CLT por meio do Decreto-Lei $n^{\circ} 229$, de 1967, que também mudou o nome do Fundo Social Sindical para Conta Especial Emprego e Salário. Concorda-se com Martins (2009), para quem a mudança de imposto sindical para contribuição sindical foi correta, tendo em vista que o referido tributo não preenche os requisitos do CTN para a sua classificação como imposto, mas ajusta-se ao tipo contribuição.

A Constituição de 1967, já sob o regime militar, em seu art. 159, § $1^{\circ}$, manteve o sistema existente, recepcionando a CLT - arts. 578 a 610 - a esse respeito. A Emenda Constitucional n 1, de 1969, art. 166, em nada inovou, mantendo-se a situação corrente. Tanto a Constituição de 1967 como a Emenda Constitucional n 1 de 1969 garantiam a liberdade sindical no Brasil, embora somente de forma retórica, haja vista que tal liberdade não se verificou na prática. Segundo Maranhão (1985, p. 305), "[...] a liberdade sindical entre nós é um mito: está na Constituição e não está na lei. Mas, o Supremo diz que esta é a que vale". Naquela época, o STF, paradoxalmente, preferiu entender ou aceitar que a lei infraconstitucional valia mais do que a Constituição. Tratou-se de uma interpretação conforme, diga-se, às avessas. A Constituição de 1988, como já referido, reconhece a contribuição sindical com natureza tributária em seu artigo 149.

A contribuição sindical obrigatória no Brasil encontra-se, portanto, vinculada ao sistema corporativista, como o braço financeiro do sistema sindical. A partir dessa constatação, a doutrina de modo majoritário ${ }^{13}$ considera essa contribuição um obstáculo significativo à adoção do

\footnotetext{
13 V.g.: Arouca (2009); Gomes e Prado (2011); Martinez (2013); Nascimento (2008); Süssekind (2005).
} 
princípio da liberdade sindical no Brasil. Gomes e Gottschalk (2005) afirmam que, mesmo que fossem eliminadas todas as demais formas de controle exercidas pelo Estado, entenda-se aí, corrigidos os dispositivos constitucionais e infraconstitucionais em contrário, bastaria a manutenção da contribuição sindical compulsória para prejudicar irremediavelmente qualquer esforço que seja feito com vistas à independência e consequentemente à liberdade e à modernização do sistema sindical brasileiro.

Delgado (2008), referindo-se às fontes de receitas dos sindicatos, afirma que a contribuição sindical obrigatória é a mais controvertida delas, do ponto de vista político-ideológico, considerando que foi prevista no regime corporativista e vem sendo mantida por várias décadas, passando por ditaduras, democracias, governos de partidos distintos - de esquerda, de centro e/ou de direita - opositores entre si, mas ninguém com poderes para tanto realmente decidiu mudá-la ou extingui-la definitivamente, embora alguns, sem muito empenho, tenham tentado. ${ }^{14}$

A dita contribuição é assim considerada como violação da liberdade sindical e contrária à modernização das relações sindicais no Brasil, sendo uma das principais causas do comodismo dos sindicalistas, da subsistência dos sindicatos de gaveta ${ }^{15}$ e de carimbo, ${ }^{16}$

14 A propósito dessa questão, Nunes (1979, p. 15) provoca uma interessante reflexão sobre o assunto: "[...] a organização sindical deixada por Getúlio reveste-se de um poder extraordinário para moldar o sindicalista aos desígnios do sistema político. Ao sentar-se à cadeira de diretor pela primeira vez, ao familiarizar-se com o mecanismo burocrático, ao começar a mexer num volume surpreendente de dinheiro - para ele, naturalmente, que antes era um simples trabalhador - 0 sindicalista em potencial se transmuda. A metamorfose de pensamento se dá naturalmente, e o antes idealista e ardoroso lutador pelas reivindicações de sua classe passa enxergar - e agir em nível do aparelho estatal. Como se deste o sindicato fosse extensão pura e simples".

15 Sindicatos de gaveta são aqueles abertos sem qualquer organização social e política. Em muitos casos, o trabalhador nem sabe que ele existe. Para sua criação, basta ser feita uma assembleia, normalmente esvaziada e convocada apenas por um edital publicado em jornal de grande circulação. A finalidade é a contribuição sindical compulsória.

16 Sindicatos de carimbo são aqueles com pouquíssima ou nenhuma representatividade, na maioria das vezes pequenos, mas eventualmente representam, apenas formalmente, grupos grandes de trabalhadores. No corporativismo, são leais ao governo, e não aos trabalhadores. São criados para receber a contribuição sindical compulsória e homologar as rescisões de contratos de trabalho. 
bem como dos sindicalistas pelegos ${ }^{17}$. Entretanto, quando se discute o fim da contribuição sindical compulsória, muitos sindicalistas levantamse em bloco na defesa dos seus interesses, alegando que o fim dessa contribuição afetaria fatalmente a sobrevivência financeira dos sindicatos. Concorda-se com Garcez (2007), ao afirmar que isto seria ótimo, pois afastaria os maus e favoreceria os bons sindicalistas.

Os sindicatos recebem a contribuição sem vinculação a nenhum tipo de contraprestação, por conseguinte têm poucos incentivos para buscar mais associados, tampouco para mobilizar a categoria na luta por conquistas para os representados. O fim da contribuição poderia expor as suas fragilidades e retirar o grande incentivo para a criação de novos sindicatos sem nenhum tipo de representatividade, abrindo espaço para os sindicatos dinâmicos e verdadeiramente defensores dos interesses dos seus representados.

Ainda segundo Garcez (2007, p. 126), em números do ano de 2007, os sindicatos receberam mais de um bilhão de reais por ano. Os números da arrecadação dos sindicatos apresentados são de 2007, portanto carecem de atualização. Segundo Oliveira (2014), em matéria do jornal O Globo (on-line), citando como fonte o Ministério do Trabalho, a receita da contribuição sindical no ano de 2013 somou $R$ \$ 3,2 bilhões, recebendo um incremento em relação ao ano anterior da ordem de $13 \%$; em 2014, a arrecadação foi de $R \$ 3,5$ bilhões - crescimento de 9,38\% sobre a arrecadação do último exercício. (ARRECADAÇÃO... Sindicato Nacional... 2015, on-line). A ausência de transparência acerca do montante arrecadado (por exemplo, a ausência dessa informação no site do Ministério do Trabalho e do uso dos recursos pelos sindicatos)

\footnotetext{
17 Sindicalistas pelegos são aqueles com pouquíssima ou nenhuma representatividade de base, com poucos associados - quanto menor o número de associados melhor -, que não querem concorrência nem nada que possa ameaçar a sua permanência no poder. Negociações no dia a dia, nem pensar, e as negociações na data base geralmente são combinadas com o sindicato patronal, cuja minuta da convenção não é levada à assembleia. A convenção é assinada por ele mesmo, sob uma suposta delegação daquela. Mobilizar os trabalhadores, de jeito nenhum, pode prejudicar os seus interesses.
} 
expõe de modo mais intenso a incompatibilidade dessa contribuição com a liberdade sindical.

Conforme Brito Filho (2009), a contribuição sindical se justificava no regime corporativista do Estado Novo, no qual o sindicato exercia funções delegadas do Estado, não fazendo mais sentido a manutenção desse instituto no momento constitucional vivenciado no Brasil. Magano (1990) critica o atual critério de repartição da receita resultante da contribuição sindical obrigatória, argumentando não haver razão, em um sistema pluralista e democrático, para que o Estado participe do recebimento da receita, se é que essa contribuição tenha que existir. Os $10 \%$ dos recursos da contribuição sindical destinados ao Estado constituem um poderoso incentivo para a sua manutenção.

Considerando-se esses posicionamentos doutrinários, conclui-se que a contribuição sindical viola a liberdade sindical em sua dimensão individual por duas razões principais: primeiro, por ser fixada em lei e, segundo, por ser compulsoriamente paga por todos os membros de uma categoria representada por um único sindicato, o qual não é escolhido pelo trabalhador.

A primeira razão diferencia a contribuição sindical de contribuições cuja cobrança e valor são determinados em assembleias de trabalhadores. Mesmo que essas contribuições, em regra, denominadas contribuições negociais, sejam pagas por todos os trabalhadores, associados ou não ao sindicato, não ferem a liberdade sindical por terem sido fixadas conforme a decisão dos próprios trabalhadores e por se justificarem pelos benefícios usufruídos por todos ealcançados pelo sindicato, em especial via negociação coletiva. A contribuição sindical compulsória tão desconectada está na negociação coletiva que difere totalmente de espécies de contribuições negociais, tanto que o art. 592 da CLT, o qual arrola os objetivos dessa contribuição, nem mesmo menciona a promoção da negociação coletiva.

Asegunda razão trata da correlação entre a unicidade e a contribuição compulsória. No Brasil, mesmo que formalmente o trabalhador seja livre para não se associar a um determinado sindicato, sua representação é imposta pelo Estado a somente uma entidade sindical. Considera-se que 
essa representação é imposta, haja vista não ser alcançada a partir de um mecanismo democrático, como a organização sindical no local de trabalho ou a assinatura de cartões de sindicalização. A partir dessa representação mandatória, o trabalhador passa a contribuir de forma obrigatória para um sindicato que não foi por ele escolhido, tendo sido determinado pelo Estado. Nada mais contrário à liberdade sindical.

3.1 Os sindicatos podem sofrer fiscalização do poder público quanto à aplicação das receitas da contribuição sindical compulsória?

Os sindicatos, embora sejam entidades privadas, sendo proibidas a interferência e a intervenção do Estado, consoante dispõe o inciso I do art. $8^{\circ}$ da Constituição Federal, são instituições que recebem uma contribuição de natureza tributária, devendo assim utilizar esses recursos no interesse dos seus representados. A CLT - art. 592 e $\S \S$ e 593, caput e parágrafo único - traça as linhas gerais de como os recursos dos sindicatos podem ser utilizados, conforme o que for aprovado pelos seus respectivos conselhos, "[...] no custeio das atividades de representação geral dos trabalhadores decorrentes de suas atribuições legais". Dessa forma, a aplicação dos supracitados recursos deve restringir-se àquilo que beneficie os trabalhadores.

Nesse sentido, Martins (2009) entende que a contribuição sindical, em razão de sua natureza tributária, tem sua receita sujeita à fiscalização do TCU. O autor desenvolve um raciocínio curioso que mostra quão anacrônica é a contribuição sindical: a fiscalização da contribuição se justifica pelo de fato de esta ter sido criada em virtude de os sindicatos, à época, exercerem funções delegadas do Estado, embora tal exercício não se verifique mais no sistema atual, o que leva à conclusão lógica de que a contribuição sindical compulsória também não mais deveria existir, embora exista, e, por existir, atrai a vigilância pública, em especial porque a aplicação da sua receita é disciplinada por lei, conforme arts. 592 e 593 da CLT, como ressaltado.

No mesmo sentido, Morais Filho (1978) afirma que a contribuição sindical compulsória, cuja natureza é reconhecidamente tributária, com 
a sua aplicação regulada em lei, está sujeita à fiscalização do TCU. Todavia, a propósito do uso indevido dos recursos da contribuição sindical pelos sindicatos, o art. 552 da CLT - em consonância com a ideia de o sindicato cumprir funções delegadas do Estado - tipifica os atos praticados pelos sindicalistas responsáveis como crime de peculato. Não obstante o supramencionado dispositivo celetista, filiase ao entendimento de Martins (2009), o qual discorda da referida tipificação, tendo em vista que o crime de peculato é próprio de servidor público, sendo mais apropriada a classificação como crime de furto ou apropriação indébita.

Arouca (2012) e Reis (2011) defendem a liberdade total para a organização sindical decidir como utilizar os recursos, desde que a contribuição seja aprovada pela assembleia geral dos trabalhadores, os quais constituiriam os mecanismos de fiscalização da aplicação dos recursos, a exemplo do conselho fiscal, entre outros. Ressalva-se que, nesse caso, não mais se trataria de contribuição sindical compulsória, mas sim de uma espécie de contribuição negocial.

A questão da possibilidade de fiscalização do uso das receitas provindas da contribuição sindical sempre está presente nas discussões acerca da utilização das receitas dos sindicatos - sobre as quais pesam muitas dúvidas, sobretudo porque há pouca publicidade, transparência e controle sobre o uso desses recursos. A pergunta frequente que se faz é se o Estado, por meio de um órgão ou instituição legitimamente constituída, pode fiscalizar a utilização destes recursos. O Supremo Tribunal Federal (STF), no Mandado de Segurança - MS n²8.465, do DF, enfrentou esta questão, a qual se passa a analisar.

O MS, sob análise, impetrado por um grupo de sindicatos de Brasília, Goiás, São Paulo e por uma federação nacional, visou desconstituir uma decisão do Plenário do STF, na qual se acatou representação do Ministério Público para autorizar os órgãos do TCU a atuarem conjuntamente com outras instituições com a finalidade de investigar indícios de incompatibilidade entre o patrimônio e a renda de dirigentes sindicais, quando a evolução patrimonial resultar de 
malversação de recursos públicos originários da contribuição sindical compulsória.

Os impetrantes argumentaram que a contribuição sindical compulsória não configura recurso público federal, bem como os sindicatos não podem ser considerados entes da administração pública direta ou indireta, de modo a atrair a competência do TCU, considerando que a competência do referido órgão limita-se ao rol exaustivo previsto nos arts. 70 e 71 da Constituição. Arguiram também ofensa ao princípio da autonomia sindical, previsto no art. $8^{\circ}$, I, da Constituição de 1988, entre outras matérias de índole processual.

O relator, Ministro Marco Aurélio Mello, indeferiu a liminar sob a fundamentação de que, entre outras questões processuais, certos pontos em questionamento desafiam a apreciação do colegiado, citando o exemplo da natureza jurídica da contribuição sindical compulsória. 0 TCU argumentou em seu favor que a natureza jurídica da contribuição sindical obrigatória é tributária (parafiscal), compreendida, portanto, na previsão do inciso $\mathrm{V}$ do art. $5^{\circ}$ da lei $n^{\circ}$ 8.443, de 1992 (Lei Orgânica do Tribunal de Contas da União) ${ }^{18}$, citando como fundamento do seu entendimento vários precedentes da Corte. O Procurador Geral da República (PGR) também opinou no mesmo sentido do TCU.

Resolvidas outras questões processuais, o ministro relator precisou solucionar a possível existência de conflito entre a autonomia sindical e a fiscalização pública. Dois pontos foram enfrentados: (I) "o sentido e o alcance da autonomia sindical" nos termos da Constituição de 1988; (II) "a natureza jurídica - pública ou privada" da contribuição sindical compulsória.

Quanto ao primeiro ponto, o relator entendeu que o constituinte, ao vedar a interferência e a intervenção do Estado na organização sindical, visou proibir que o Estado agisse como antes da Constituição de 1988,

18 Inciso $V$ do art. $5^{\circ}$ da Lei $n^{\circ} 8.443$ de 1992 , sobre a abrangência da competência do TCU: "os responsáveis por entidades dotadas de personalidade jurídica de direito privado que recebam contribuições parafiscais e prestem serviço de interesse público ou social". 
período em que havia um forte dirigismo estatal, com a utilização política dos sindicatos. Essa garantia, no entendimento do Min. Relator, somente protege a organização interna do sindicato em face de "[...] eventuais influxos do poder público". Em relação às suas deliberações referentes às pautas de reivindicações, greves, eleições, negociações coletivas, etc., não blindam o sindicato em face da ação dos agentes estatais em serviço na defesa do interesse público. O ministro relator, fundamentadamente, decidiu por ser inaceitável que a autonomia sindical tenha o condão de impedir as funções fiscalizatórias do poder público. Afirma que a "[...] autonomia sindical não é salvo-conduto, mas prerrogativa direcionada a certa finalidade - a plena e efetiva representação das classes empregadora e empregada". (BRASIL, STF, MS n² 28.465, 2014, publ.: 3.4.2014). Portanto, de forma clara, o Ministro Marco Aurélio decidiu que os recursos provenientes da contribuição sindical podem ser fiscalizados pelas instituições e órgãos do Estado.

Ainda consoante a jurisprudência citada, quanto ao segundo ponto - natureza jurídica da contribuição sindical compulsória -, o ministro relator cita a redação dos arts. 578 e 579 da CLT, destacando a antiga redação que tratava do "imposto sindical", posteriormente rebatizado de contribuição sindical, sem, contudo, ter as suas características alteradas: ainda continua a ser uma "[...] prestação pecuniária de natureza compulsória, sem estipular qualquer contrapartida, decorrente do simples fato de pertencer a uma categoria econômica ou profissional, ou de profissão liberal, destinando-a a categoria". Segundo o relator, essa definição encaixa-se perfeitamente na definição de tributo prevista no art. $3^{\circ}$ do CTN. O Ministro Marco Aurélio conclui não restar dúvida de que a contribuição sindical compulsória tem natureza jurídica tributária, bem como de que os valores arrecadados são de caráter público, por serem oriundos de tributação a todos imposta.

Quanto à competência do TCU, o ministro relator afirma também não ter dúvida, citando os arts. 70 e 71 da Constituição e a Lei n 8.443 , de 1992 , em especial o inciso $V$ do art. $5^{\circ}$, que, ao se referir ao elenco de entidades que estão submetidas à competência do TCU, assim dispõe: "[...] os responsáveis por entidades dotadas de personalidade 
jurídica de direito privado que recebem contribuições parafiscais e prestem serviço de interesse público ou social". Dessa forma, o STF decidiu que a contribuição sindical compulsória tem natureza tributária, constituindo receita pública, estando os responsáveis sujeitos à competência fiscalizatória do Tribunal de Contas da União, sem que isso fira a autonomia sindical prevista na Constituição. (BRASIL, STF, MS nº 28.465, 2014, publ.: 3.4.2014).

Concorda-se com a supracitada decisão do STF, inobstante entender-se que a contribuição sindical compulsória deva ser abolida, dando lugar a outra espécie de contribuição para o custeio das atividades sindicais, desta feita negociada e aprovada em assembleia geral dos trabalhadores. Nesse caso, é possível, inclusive, a cobrança aos não associados, desde que beneficiários das conquistas. Esse posicionamento é aceito pela OIT. De qualquer modo, enquanto persistir a contribuição sindical obrigatória por lei, sobretudo pelas razões declinadas no voto do iminente relator, o Estado, por intermédio do TCU, conjuntamente com outras instituições públicas autorizadas, pode e deve fiscalizar a aplicação dos recursos provenientes do referido tributo.

\section{A contribuição assistencial sindical e o caso 2739 (Brasil) do Comitê de Liberdade Sindical da OIT}

A contribuição assistencial sindical, atualmente, refere-se a uma contribuição a ser custeada pelos trabalhadores de determinada categoria profissional em favor do seu respectivo sindicato, por ocasião do primeiro pagamento reajustado com o índice que houver sido resultado da negociação coletiva ou em algumas parcelas, conforme negociado.

Essa contribuição surgiu como uma expressão da burocratização dos sindicatos, que passaram a cuidar de serviços assistenciais, como planos de saúde, planos odontológicos, colônia de férias (AROUCA, 2012). Entretanto, no final dos anos 1970, essa fonte de receita passou a servir a outros propósitos, reforçando os sindicatos na criação de 
fundo de greve, criação de subsedes e delegacias, investimento em formação e treinamentos, financiamento de campanhas por direitos, e.g.: campanha pela redução da jornada de trabalho, entre outros. ${ }^{19}$

Embora tenha uma previsão genérica na CLT, art. 513, alínea $e$, esse recolhimento é subordinado à aprovação em assembleia geral dos trabalhadores. Ademais, a jurisprudência do TST e do STF vem entendendo que essa contribuição somente pode ser cobrada de trabalhadores associados, haja vista já existir a contribuição sindical compulsória que a todos alcança. Nesse sentido, a OJ $n^{\circ} 17$ da SDC do TST, a Súmula $n^{\circ} 666$ - recentemente convertida na Súmula Vinculante $n^{\circ} 40$, ambas do STF, bem como o Precedente Normativo-PN n 119 do TST. ${ }^{20}$

Delgado (2008), no entanto, entende que, inobstante essa tendência interpretativa, a qual libera os não associados da contribuição, se no instrumento coletivo que a houver aprovado tiver expressa a possibilidade de objeção por parte dos trabalhadores não sindicalizados, esta poderia ser aceita. Conforme o autor, não seria razoável que somente os sindicalizados pagassem os custos do sindicato em decorrência de uma negociação que a todos beneficiou.

A falta de consenso entre a doutrina, as cortes e os sindicatos acabou levando essa questão à OIT, mais especificamente ao Comitê de Liberdade Sindical, no caso n² 2739 (Brasil), em 2 de novembro de 2009. O principal motivo remonta à insatisfação das organizações sindicais com as medidas adotadas pelo Ministério Público do Trabalho (MPT),

19 Segundo Delgado (2008), a contribuição também recebe outras denominações, como "taxa de reforço sindical, contribuição de fortalecimento sindical, etc".

20 Observe-se O PN 119: PN-119 CONTRIBUIÇÕES SINDICAIS - INOBSERVÂNCIA DE PRECEITOS CONSTITUCIONAIS - (mantido) DEJT divulgado em 25.08.2014 A Constituição da República, em seus arts. $5^{\circ}, \mathrm{XX}$ e $8^{\circ}, \mathrm{V}$, assegura o direito de livre associação e sindicalização. É ofensiva a essa modalidade de liberdade cláusula constante de acordo, convenção coletiva ou sentença normativa estabelecendo contribuição em favor de entidade sindical a título de taxa para custeio do sistema confederativo, assistencial, revigoramento ou fortalecimento sindical e outras da mesma espécie, obrigando trabalhadores não sindicalizados. Sendo nulas as estipulações que inobservem tal restrição, tornam-se passíveis de devolução os valores irregularmente descontados. 
em São Paulo, contra a fixação de cláusulas de contribuição assistencial para toda a categoria (GACEK e NICOLADELI, 2014), bem como com as decisões proferidas pelo Poder Judiciário brasileiro revogando cláusulas de convenções coletivas relativamente ao pagamento de contribuições assistenciais sindicais por trabalhadores, incluindo os não sindicalizados.

O argumento das entidades sindicais é que esses trabalhadores teriam sido beneficiados pelas conquistas da convenção coletiva. A queixa também argui que o Ministério Público do Trabalho em São Paulo iniciou procedimentos legais com a finalidade de prevenir o engajamento dos trabalhadores em ações de protestos organizadas pelos sindicatos, o que caracterizaria ações antissindicais, prática combatida pela OIT.

O caso $n^{\circ} 2739$ teve a sua apreciação iniciada pelo Comitê de Liberdade Sindical em novembro de 2011. Posteriormente, em fevereiro de 2012, o governo brasileiro enviou ao Comitê observações por meio de um comunicado. O Comitê ressaltou que o Brasil não ratificou a Convenção $n^{\circ} 87$, mas somente a Convenção $n^{\circ} 98$, ambas da OIT. O Comitê sugeriu ao governo a iniciativa de estabelecer uma comissão tripartite para tratar de questões de relações industriais. Lembrou também que o governo brasileiro pode pedir a assistência da OIT na busca de soluções que sejam satisfatórias para as partes e que estejam em conformidade com os princípios da liberdade sindical.

O Comitê pediu explicações ao governo brasileiro acerca das alegações de que o MPT em São Paulo estaria realizando procedimentos legais com vistas a prevenir o engajamento dos trabalhadores em ações de protestos organizadas pelos sindicatos. Também recomendou iniciar um diálogo envolvendo a maior representação possível dos empregadores e dos trabalhadores acerca do assunto. Por último, o Comitê convidou o governo brasileiro a considerar as necessárias medidas para a ratificação da Convenção n 87 da OIT (ILO, 2012, tradução nossa).

A resposta governamental, por meio do MPT, afirma que, desde 2009, o MPT mantém a Coordenadoria Nacional da Liberdade Sindical 
(CONALIS), operando como um canal de comunicação aberto com os sindicatos representantes dos trabalhadores; há uma CONALIS em cada unidade do MPT, com vistas a fortalecer os sindicatos e criar um ambiente que conduza ao exercício da liberdade sindical. O MPT relata que a CONALIS realizou inúmeros encontros com os sindicatos para discutir vários assuntos, inclusive a arrecadação de contribuições de trabalhadores sindicalizados e não sindicalizados, acertadas em convenções e acordos coletivos.

Os sindicatos não concordaram com as medidas adotadas pelos procuradores objetivando declarar nulas e inválidas tais cláusulas convencionais. O MPT afirma que a Lei Complementar $n^{\circ} 75$, art. 83, IV, de 1993, autoriza-o a propor os procedimentos necessários para a proteção de direitos constitucionais, qualquer medida para declarar nula e inválida cláusula de convenção ou acordo coletivo ou contrato que viole liberdades individuais ou coletivas, ou direitos individuais inalienáveis dos trabalhadores. Como as jurisprudências do STF e do TST não autorizam a arrecadação desse tipo de contribuição, justificase a atuação do MPT.

Ainda de acordo com o MPT, o art. $8^{\circ}$ da Constituição do Brasil não apenas garante a liberdade positiva de associação como também a negativa, o que significa que ninguém é obrigado a filiar-se ou a manterse filiado a sindicato. Além disso, a Jurisprudência do STF assegura que a contribuição confederativa prevista no art. $8^{\circ}$ da Constituição somente é aplicável aos respectivos membros do sindicato. O TST vai além, ao afirmar que qualquer cláusula de acordo, convenção coletiva ou sentença normativa que obrigue trabalhador não sindicalizado a pagar a taxa confederativa, contribuição assistencial, contribuição promocional ou outra similar para sindicato deve ser considerada uma contravenção a liberdade ou a direitos. Qualquer previsão desconforme com essa restrição deve ser declarada nula e inválida, e os valores irregularmente retidos devem ser devolvidos aos respectivos trabalhadores. (ILO, 2012, tradução livre). 
O MPT acrescentou que, no encontro de maio de 2010, após vários outros encontros com os representantes dos sindicatos, apesar da jurisprudência em favor das medidas do MPT contra a arrecadação de contribuições assistenciais de trabalhadores não sindicalizados, a CONALIS discutiu o assunto e aprovou a Orientação $n^{\circ} 3$, regulamentando que contribuições assistenciais negociadas podem ser arrecadadas de trabalhadores sindicalizados e não sindicalizados, desde que tenha sido aprovada em assembleia geral, realizada para essa finalidade, para a qual tenha sido dada ampla publicidade, com todas as informações de local, horário etc., e dadas as facilidades para que os trabalhadores possam participar, garantido o direito de objeção e que esta possa ser apresentada por qualquer meio de comunicação, entre outros.

De acordo com o MPT, a adoção da Orientação objetivou que o movimento sindical considerasse a necessidade do compromisso com as instituições envolvidas, apesar da total falta de suporte jurisprudencial. A decisão foi considerada satisfatória pelos sindicatos. A expectativa era a de que essa medida diminuiria a tensão entre o MPT e as entidades sindicais. Ademais, esperava-se que a Orientação $n^{\circ} 3$ do MPT gerasse um debate no sentido de reverter a jurisprudência acerca da arrecadação de contribuições assistenciais de trabalhadores não sindicalizados. Contudo, não foi o que se verificou na prática.

O MPT relata que um sentimento de resistência começou a se desenvolver entre os procuradores a respeito da posição adotada na Orientação $n^{\circ} 3$ e duras críticas foram direcionadas à regra que havia sido aprovada. As críticas relacionam-se a: (a) o abuso de coletar contribuições de trabalhadores não sindicalizados, aos quais não foi dado o direito de objeção; (b) o fato de os trabalhadores já terem que pagar uma contribuição compulsória, independentemente de serem membros do sindicato; (c) a ausência de qualquer contabilidade por parte dos sindicatos, apesar da natureza pública da contribuição; (d) o fato de que as medidas adotadas pelo MPT prevenindo abuso estariam prejudicadas; (e) a ausência de qualquer movimento da Corte trabalhista para mudar a jurisprudência. Além disso, o movimento sindical começou a utilizar a Orientação $n^{\circ} 3$ para argumentar contra a ação dos procuradores, o que teria gerado ainda 
maior tensão. Esse movimento teria criado a necessidade de a referida Orientação ser revista, e, em agosto de 2011, após extensivos debates e consultas, a maioria dos procuradores decidiu retirar a Orientação $n^{\circ} 3$. Afirmam que, apesar de todo o esforço da CONALIS para encontrar uma posição de compromisso com o movimento sindical a esse respeito, o resultado não foi o esperado (ILO, 2012, tradução livre).

O MPT relata que algumas observações podem ser feitas a respeito dos eventos ocorridos: (1) o diálogo entre o MPT e o movimento sindical deve continuar; (2) o movimento sindical já teria sido advertido e informado sobre as dificuldades para a adoção de uma posição em favor da cobrança da contribuição assistencial sindical dos não sindicalizados, se não houver mudanças na legislação e na jurisprudência; (3) dentro do contexto do diálogo, notou-se que, sem que se modifique o sistema sindical brasileiro, será muito difícil aceitar a arrecadação de contribuição assistencial de trabalhadores não sindicalizados; (4) a modificação do sistema sindical brasileiro envolverá a ratificação da Convenção $n^{\circ}$ 87 da OIT, a modificação da legislação estabelecendo critérios para a representatividade sindical, promovendo benefícios para as organizações mais representativas, e previsão para mecanismos privados de financiamento sindical, que poderá autorizar aos trabalhadores não sindicalizados contribuir voluntariamente para que possam se beneficiar das conquistas e das condições de trabalho resultantes da ação sindical por meio das negociações coletivas. Finalmente, o MPT reafirma que permanece à disposição para manter um canal de comunicação aberto entre a CONALIS e o movimento sindical, de forma que possam trabalhar juntos para assegurar melhores condições de trabalho e prevenir abusos e violações a direitos sagrados no sistema legal brasileiro e nas convenções da OIT (ILO, 2012, tradução nossa).

Nas suas conclusões, o Comitê explicou que, conforme o debate ocorrido a tempo da negociação da Convenção $n^{\circ} 98$ da OIT, esta instituição internacional se posicionou no sentido de que: essa convenção não deveria ser interpretada como contendo uma proibição ou autorização de cláusulas de segurança sindical (espécie de contribuição negocial) e que questões advindas desse debate deveriam 
ser solucionadas conforme o sistema jurídico e as práticas nacionais. Por fim, o Comitê ressalta que quando a legislação admite cláusulas de segurança sindical, como a retenção de contribuições sindicais dos salários dos não-associados que se beneficiaram da conclusão de um acordo coletivo, essas cláusulas só devem ter efeito se aprovadas pela assembleia geral dos trabalhadores ${ }^{21}$ (ILO, 2012, tradução nossa).

Gacek e Nicoladeli (2014) argumentam que essa conclusão permite arguir que as contribuições negociais fixadas em acordos e convenções coletivas, mesmo sendo cobradas de trabalhadores não associados, não violam o princípio da liberdade sindical, se estiverem de acordo com as práticas e a legislação nacional. Os autores citam, ainda, o artigo 513, alíneas $b$ e e, como fundamentos jurídicos para cobrança da contribuição negocial.

Concorda-se com essa conclusão no sentido de que a contribuição assistencial negocial, cobrada de todos os trabalhadores beneficiados pela negociação coletiva, promove a liberdade sindical e a plena negociação coletiva, uma vez que encoraja a filiação sindical e garante a subsistência econômica do sindicato. ${ }^{22}$ Discorda-se, no entanto, que no contexto brasileiro essa análise possa se dar de forma isolada, ou seja, não se pode ignorar que o mesmo sindicato que negocia a contribuição assistencial tem sua representação advinda da unicidade sindical e já recebe a contribuição sindical compulsória. É esse o contexto também considerado pelo MPT. O que se defende é que a contribuição negociada, aprovada pelos próprios trabalhadores, como previsto no art. $7^{\circ}$ da Lei $\mathrm{n}^{0} 11.648$ de 2008, substitua a contribuição sindical.

21 No original, em inglês: "[...] when legislation admits trade union security clauses, such as the withholding of trade union dues from the wages of non-members benefiting from the conclusion of a collective agreement, those clauses should only take effect through collective agreements" (International L. ... ILO, 2012, p. 4-5).

22 'As leis 'right to work' nos Estados Unidos que permitem que trabalhadores se recusem a cumprir cláusulas de segurança sindical, ou seja, de pagar contribuições negociais mesmo que beneficiados pela negociação coletiva nos parece uma ameaça à própria existência do sindicato" (RIGHT ..., 2015, on-line). 
A estrutura corporativista e não representativa do sindicato brasileiro permite práticas claramente antissindicais cometidas no afã de se arrecadar mais recursos, livres do controle dos trabalhadores representados ou, ainda, do Poder Público, no caso da contribuição sindical. Como forma de fazer face aos obstáculos criados pela Jurisprudência do TST e do STF, Romita (2007) explica que sindicatos de trabalhadores acordam com o sindicato patronal na convenção coletiva, sem a anuência dos trabalhadores, que as empresas abrangidas pela respectiva categoria pagarão ao sindicato dos empregados, sem nada descontar dos trabalhadores, um determinado percentual sobre a folha de pagamento, como forma de compensar o sindicato laboral por não poder cobrar a contribuição assistencial sindical. ${ }^{23}$ Essa prática é tão frequente que motivou a edição do Enunciado $n^{\circ} 27$ da $1^{\text {a }}$ Jornada de Direito Material e Processual na Justiça do Trabalho, nov-2007, a saber:

\author{
27. CONDUTA ANTI-SINDICAL. FINANCIAMENTO PELO \\ EMPREGADOR. \\ VEDAÇÃO. É vedada a estipulação em norma coletiva \\ de cláusula pela qual o empregador financie a atividade \\ sindical dos trabalhadores, mediante transferência de \\ recursos aos sindicatos obreiros, sem os correspondentes \\ descontos remuneratórios dos trabalhadores da categoria
}

23 Nesse sentido, atente-se para o acórdão a seguir: "Ementa: Taxa de participação na negociação coletiva a cargo da empresa a ser carreada aos cofres do sindicato profissional. Manutenção de organização sindical de trabalhadores com recursos financeiros da empresa. Comprometimento da autonomia sindical e da missão de representação dos interesses e direitos dos trabalhadores. Nulidade da cláusula da Convenção Coletiva de Trabalho. Malferimento às regras encravadas na Convenção n. 98, da OIT e nos princípios constitucionais da autonomia sindical (art. $8^{\circ}, 1$ ), da representação dos interesses e direitos da categoria profissional (art. $8^{\circ}, \mathrm{VI}$ ). O desiderato das normas internacionais e constitucionais citadas é o de garantir a liberdade sindical frente ao Estado, ao empregador e às organizações sindicais contrapostas, de modo a evitar o domínio, o controle, a dependência, a cooptação e a promiscuidades na relação sindical. Ofende a Convenção n. 98, da OIT (ratificada pelo Brasil) e a Constituição Federal de 1988 (art. $8^{\circ}$, I, III, e $\mathrm{VI}$ ) cláusula de convenção coletiva de trabalho que tem por escopo estabelecer remuneração, a ser paga pela empresa, pela participação do sindicato profissional na negociação coletiva. Com efeito, a entidade sindical profissional, associação sem fins lucrativos, representa e negocia por imposição de um dever constitucional, verdadeiro múnus público, e portanto deve buscar a defesa dos interesses e direitos da coletividade de trabalhadores pertencentes à categoria e não interesses financeiros próprios. TRT/SP - 02769200305602007 - RO - Ac. T. 20060722821 Rel. Ivani Contini Bramante. (ROMITA, 2007, p. 667). 
respectiva, sob pena de ferimento ao princípio da liberdade sindical e caracterização de conduta antissindical tipificada na Convenção $n^{\circ} 98$ da OIT, ratificada pelo Brasil.

Fica claro que há desvios importantes neste tipo de cobrança, inconciliáveis com a autonomia sindical prevista na Constituição e com a Convenção n 98 da OIT, ratificada pelo Brasil. Eis alguns dos motivos pelos quais os tribunais têm obstaculizado a dita contribuição. Portanto, fica clara a necessidade de uma reforma no sistema sindical brasileiro, em particular nas suas formas de custeio, eliminando-se os resquícios corporativistas e o seu caráter autoritário, privilegiando-se a liberdade sindical.

\section{Conclusão}

A contribuição sindical compulsória, de natureza tributária, não deveria mais existir por se contrapor a um sistema democrático e plural de representação sindical, devendo ser substituída por uma forma privada e democrática de financiamento dos sindicatos. Todavia, enquanto esta existir, necessário se faz o controle sobre a aplicação dos recursos dela provenientes. Dessa forma, concorda-se com a decisão do STF que autorizou o TCU, o qual poderá atuar conjuntamente, se necessário, com outras instituições/órgãos públicas autorizadas, a auditar as contas dos sindicatos, notadamente quanto à utilização das receitas da contribuição sindical imposta por lei.

Analisando-se o caso 2739 (Brasil), de 2009, do Comitê de Liberdade Sindical da OIT, observa-se que a OIT admite a cobrança de taxa de solidariedade (como, por exemplo, contribuição assistencial), a ser custeada por trabalhadores não associados que teriam sido beneficiados pela negociação coletiva. Isto se justifica por não ser justo que somente uma parte dos trabalhadores contribua financeiramente para o sindicato, dando suporte às campanhas por melhorias para a categoria, enquanto outros trabalhadores fiquem isentos da contribuição, mas, mesmo assim, sejam beneficiados pelas vantagens auferidas pela ação da entidade sindical. 
Portanto, segundo a OIT, mesmo uma contribuição compulsória pode ser considerada democrática, desde que o sindicato que a instituiu seja um sindicato representativo, com base democrática, e que a cobrança tenha por base uma decisão da assembleia. Diante do contexto nacional brasileiro, no entanto, deve-se adicionar à análise da OIT que a contribuição negocial, se somada à já existente e compulsória contribuição sindical, adquire contorno de um ato abusivo praticado pelo sindicato contra os próprios trabalhadores.

\section{Referências}

ALMEIDA, Renato Ruas de. Visão histórica da liberdade sindical. Revista LTr, São Paulo, v. 70, n. 3, p. 363-366, mar. 2006.

AROUCA, José Carlos. Organização sindical: pluralidade e unicidade. Fontes de custeio. Revista do Tribunal Superior do Trabalho, Brasília, v. 78, n. 2, p. 84-96, abr./jun. 2012.

2009.

. Curso básico de direito sindical. 2. ed. São Paulo: LTr,

ARRECADAÇÃO com contribuição sindical cresce 9,4\% em 2014 e atinge $\mathrm{R} \$ 3,5$ bi. Sindicato Nacional dos Funcionários do Banco Central. Brasília, 2015. Disponível em: <http://portal.sinal.org.br/ noticias-recentes/arrecadacao-com-contribuicao-sindical-cresce-94em-2014-e-atinge-r-35-bi/>. Acesso em: 10 fev. 2016.

BERNARDES, Hugo Greiros. Níveis de negociação coletiva. In: PRADO, Ney (Coord.). Direito Sindical Brasileiro. São Paulo: LTr, 1998.

BRASIL. Supremo Tribunal Federal - STF. RE 466.343-1, SP. Brasília, DF, Supremo Tribunal Federal. 2008. Disponível em: <http://redir. stf.jus.br/paginadorpub/paginador.jsp?docTP=AC\&doclD=595444>. Acesso em: 8 dez. 2014.

RE 180.745-8, SP. Brasília, DF, Supremo Tribunal Federal. 1998. Disponível em: <http://redir.stf.jus.br/paginadorpub/paginador. jsp?docTP=AC\&docID=225529>. Acesso em: 8 dez. 2014. 
. MS 28.465, DF. Brasília, DF, Supremo Tribunal Federal.

2014. Disponível em: <http://redir.stf.jus.br/paginadorpub/paginador. jsp?docTP=TP\&doc ID=5569587>. Acesso em: 8 dez. 2014.

BRITO FILHO, José Cláudio Monteiro de. Direito sindical. 3. ed. São Paulo: LTr, 2009.

DELGADO, Maurício Godinho. Direito coletivo do trabalho. 3. ed. São Paulo: LTr, 2008.

GACEK, Stanley. A declaração sobre princípios e direitos fundamentais no trabalho da OIT de 1998 dezesseis anos depois: seu significado para a liberdade sindical e a negociação coletiva no Brasil e no mundo: comentários adicionais a debate permanente. In: GOMES, A. V. M.; FREITAS JUNIOR, A. R. (Org.). A Declaração de 1998 da OIT sobre princípios e direitos fundamentais no trabalho: análise do seu significado e efeitos. São Paulo: LTr, 2014. p. 113-132.

GACECK, Stanley; NICOLADELI, Sandro Lunard. "Liberdade sindical no Brasil e a OIT: a questão da cláusula assistencial do precedente normativo 119 ao Caso 2739. Jornal Digital do $54^{\circ}$ Congresso Brasileiro de Direito de Trabalho. São Paulo: Ltr, 2014. Disponível em: <http://www.ltr.com.br/congressos/jornal/direito/jornal_direito.pdf>. Acesso em: 11 mar. 2015.

GARCEZ, Edmir de Freitas. Negociando com negociadores: o negociador trabalhista. São Paulo: do Autor, 2007.

GOMES, Ana Virgínia Moreira; PRADO, Mariana Mota. Flawed freedom of association in Brazil: how unions can become an obstacle to meaningful reforms in the labor law system. Comparative Labor Law \& Policy Journal, Toronto, v. 32, n. 4, p. 843-889, 2011.

GOMES, Eduardo Biacchi; PRZYBYZESKI, Silvana. O Supremo Tribunal Federal e a aplicação dos tratados de direitos humanos. Pensar: Revista de Ciências Jurídicas, Fortaleza, v. 19, n. 3, p. 614646, set./dez. 2014.

GOMES, Orlando; GOTTSCHALK, Élson. Curso de direito do trabalho. 17. ed. Rio de Janeiro: Forense, 2005. 
INTERNATIONAL LABOUR ORGANIZATION - ILO. Definitive Report - Report n 364, June 2012, Case n² 2739 (Brazil), § 332. p. 337-348. Disponível em: <http://www.ilo.org/dyn/normlex/en/f?p=NORMLEXP UB:50002:0::NO::P50002_COMPLAINT_TEXT_ID,P50002_LANG_ CODE:3063459,en>. Acesso em: 10 nov. 2014.

MAGANO, Octávio Bueno. Manual de direito do trabalho. 2. ed. São Paulo: LTr, 1990. v. 3. (Direito Coletivo do Trabalho).

MARANHÃO, Délio. Direito do trabalho. 13. ed. Rio de Janeiro: Fundação Getúlio Vargas, 1985.

MARTINEZ, Luciano. A contribuição sindical obrigatória como conduta violadora da liberdade sindical individual negativa. In: Alvarenga, R. Z.; Teixeira, E. F. (Org.). Novidades em direito e processo do trabalho. São Paulo: LTr, 2013. p. 337- 348.

MARTINS, Sergio Pinto. Contribuições sindicais: direito comparado e internacional; contribuições assistencial, confederativa e sindical. 5. ed. São Paulo: Atlas, 2009.

MORAES FILHO, Evaristo de. O problema do sindicato único no Brasil: seus fundamentos sociológicos. 2. ed. São Paulo: Alfa-Omega, 1978.

NASCIMENTO, Amauri Mascaro. Compêndio de direito sindical. 5. ed. São Paulo: LTr, 2008.

NUNES, Antônio Carlos Felix. Além da greve. São Paulo: Jornalística Criart, 1979.

OLIVEIRA, Germano. Sindicatos receberam R 3.2 bi de imposto em 2013, alta de 13\%. O Globo, Rio de Janeiro, 29 mar. 2014. Disponível em: <http://oglobo.globo.com/economia/sindicatos-receberam-32-bide-imposto-em-2013>. Acesso em: 29 set. 2014.

REIS, Daniela Muradas. A imposição da contribuição sindical e o princípio da liberdade associativa: reflexões sobre o regime democrático e o financiamento sindical brasileiro. Revista Síntese 
Trabalhista e Previdenciária, São Paulo, v. 23, n. 268, p. 18-33, out. 2011.

RIGHT to work is anything but. Charleston Gazette, West Virginia USA, 9 feb. 2015. Monday: 958 words. LexisNexis Academic, Web, 2015.

ROMITA, Arion Sayão. A (des)organização sindical brasileira. Revista Legislação do Trabalho, São Paulo, v. 71, n. 6, p. 666-675, jun. 2007. SÜSSEKIND, Arnaldo. Direito constitucional do trabalho. 3. ed. Rio de Janeiro: Renovar, 2004.

et al. Instituições de direito do trabalho. 22. ed. São Paulo: LTr, 2005. v. 2.

Recebido em: 01/06/2015

Aprovado em: 25/11/2015 